\title{
Treatment of Heredo-Degenerative Ataxias with Amantadine Hydrochloride
}

\author{
M.I. Botez, Simon N. Young, Thérèse Botez and Olga L. Pedraza
}

\begin{abstract}
Amantadine hydrochloride (AH) was administered (200 mg/day) for more than three months to 17 patients with Friedreich's ataxia (FA) and to 12 patients with olivopontocerebellar atrophies (OPCA) in an open clinical trial. Reaction time (RT) and movement time (MT) with the right and left hand were measured before and after treatment. A striking improvement on both RT and MT was observed in the OPCA group (on seven out of eight measures), whereas in the FA patients improvement was seen only in two out of four MT measures with no improvement in RT. Both groups had low levels of homovanillic acid (HVA) in their cerebrospinal fluid before treatment, relative to their controls. However, improvement with AH was not related to HVA levels.
\end{abstract}

RÉSUMÉ: Traitement des ataxies hérédo-dégénératives par le chlorhydrate d'amantadine. Lors d'une étude clinique ouverte, on a administré du chlorhydrate d'amantadine (CA, $200 \mathrm{mg}$ par jour) chez 17 patients avec ataxie de Friedreich (AF) et chez 12 patients avec atrophies olivopontocérébelleuses (AOPC). Le temps de réaction (TR) et le temps de mouvement (TM) ont été mesurés (pour la main droite et la main gauche) avant et après le traitement. Nous avons remarqué une amélioration évidente autant au TR qu'au TM chez les patients avec AOPC (pour 7 sur 8 mesures), tandis que chez les patients avec AF l'amélioration a été retrouvée seulement pour deux mesures du TM (sur 4) sans aucune amélioration au TR. Bien que les deux groupes de patients avaient des valeurs basses de l'acide homovanillique (AHV) dans le liquide céphalo-rachidien avant le traitement, l'amélioration avec le CA ne semble pas être reliée strictement avec les valeurs de AHV.

Can. J. Neurol. Sci. 1991: 18: 307-311

Anatomical and behavioral neurochemical work on degenerative disorders has led to therapies which replace or potentiate the function of those neurotransmitters whose neurons have degenerated. This approach has triumphed mainly in Parkinson's disease, but it has not been of any use in Alzheimer's disease.

In a preliminary study, we found low levels of the dopamine metabolite, homovanillic acid (HVA), in the cerebrospinal fluid (CSF) of patients with both Friedreich's ataxia (FA) and olivopontocerebellar atrophies (OCPA). 1,2 Because amantadine hydrochloride $(\mathrm{AH})$ is known to stimulate dopamine release, ${ }^{3}$ this finding prompted us to test $\mathrm{AH}$ in FA and OPCA. An improvement in reaction time (RT) and movement time (MT) was seen in three FA and two OPCA patients. In an independent study, Petersen et al. ${ }^{4}$ reported a beneficial effect of $A H$ in FA patients in an open clinical trial.

The aim of the present open clinical trial was two-fold: 1) to evaluate the therapeutic effect of AH separately in FA and OPCA patients using RT and MT measures; and 2) to determine whether the beneficial effects of AH are related to CSF HVA levels.

\section{Patients}

A neurological examination was performed independently by two neurologists (M.I.B. and O.L.P.). In addition to the routine neurological examination, in order to rule out mild parkinsonian rigidity, we also looked for signs of latent muscular parkinsonian rigidity as described by Noica and Draganesco. 5 With the patient in a relaxed recumbent position, the examiner holds the patient's forearm upright; he then elicits complete and continuous passive flexion and extension of the wrist. After 10-12 sec, the subject is asked to perform a voluntary slow movement with another limb, as, for example, raising a lower limb in the air. During such a manoeuvre, increasing local tonus gradually inhibits passive wrist movements. This increased resistance disappears after the patient returns to the initial relaxed state. In our experience, it is the most sensitive and pathognomonic clinical sign of early parkinsonian rigidity. 6

$\mathrm{X}$-ray-computed tomographic (CT) scans were taken of all patients with an Elscint apparatus. ${ }^{7}$ Those showing central (i.e. ventricular dilation) and cortical (i.e. cortical sulci dilation) atrophies according to previously-defined radiological criteria, were excluded, so that only patients with well-delimited cerebellar damage underwent CSF HVA measurements. Other patients excluded from the study were alcoholics and epileptics, OPCA cases with mild parkinsonian signs, individuals with corrected visual acuity of less than $5 / 10$ in one eye and subjects with cardiomyopathies and cardiac arrhythmias.

From the Laboratory of Clinical Neuropsychology and Behavioral Neurology, Neurology Service, Hôtel-Dieu Hospital, Université de Montréal; and the Department of Psychiatry, McGill University, Montréal

Received August 8, 1990. Accepted January 5, 1991

Reprint requests to: Dr. M.I. Botez, Neurology Service, Hôtel-Dieu de Montréal, 3840 St-Urbain Street, Montréal, Québec, Canada H2W IT8 
Hand grip strength was evaluated with the Smedley dynamometer; ${ }^{8}$ those who were unable to demonstrate a minimum grip strength of $5 \mathrm{~kg}$ with each hand were considered to have severe motor disturbances and consequently were ruled out from the study. The rationale for this decision was based on the fact that subjects with a grip strength of $5 \mathrm{~kg}$ and more can easily develop a minimum force of $5 \mathrm{~g}$ to press a key for RT measurements.

The 17 FA patients ( 8 women and 9 men) included in the trial were $29.4 \pm 7.5$ years old $(X \pm S D)$. The duration of their disease was $18.4 \pm 7.2$ years. Treatment ranged from 1.5 to 26 months, i.e. $\mathrm{X} \pm \mathrm{SD}=7.9 \pm 7$ months. Eleven were confined to a wheel chair and the other six had a severe ataxic gait. All fulfilled the diagnostic criteria of Harding. ${ }^{9}$ They had a cerebellar syndrome involving the upper extremities. All had polyneuropathies and three were diabetic. All were right handed.

The 12 OPCA patients ( 7 women and 5 men) in the trial were $45.6 \pm 15.5$ years old $(X \pm S D)$ and the duration of their disease was $19.7 \pm 14.2$ years; treatment ranged from 4 to 23 months, i.e. $\mathrm{X} \pm \mathrm{SD}=8.9 \pm 6.0$ months. Assessed by the classification of Huang and Plaitakis, 10 two had dominant form 3 OPCA (type "S" family), four had dominant form 5 OPCA (associated with slow or absent ocular saccades), two had sporadic forms, while the remaining four had a recessive form. Four patients had polyneuropathies. All were right-handed and all were ambulatory and ataxic.

The condition of these patients was stable, and they had no other medical or neurological disease in evolution. No parkinsonian signs, chorea, dysphagia, ophthalmoplegia, amyotrophy or sphincter disturbances were evident, in keeping with the absence of non-cerebellar lesions on the CT scans. In particular, 10 of the 12 OPCA patients displayed frank hypotonia whereas two others had normal muscle tone.

\section{METHOdS}

A complete history and physical examination of each patient was videotaped. RT and MT testing was undertaken at least two days before AH treatment was started. A spinal tap was also carried out on all patients before the initiation of treatment. All FA patients underwent clinical cardiological evaluation with electrocardiograms (ECG), echocardiograms (ECOG) and radioisotope ventriculography, before entering the trial. Assessment after treatment included a physical examination, RT and MT testing and, for the FA patients, clinical examination by a cardiologist with ECG and ECOG. All patients were hospitalized during the spinal tap, the clinical examinations, and RT and MT testing.

All of them received $100 \mathrm{mg}$ of $\mathrm{AH}$ per day for the first week and $200 \mathrm{mg}$ per day thereafter. Therapy was continued for at least 3.5 months, with the exception of one FA patient who was treated for only 1.5 months because $\mathrm{AH}$ induced nightmares and gastrointestinal side-effects. At the end of the clinical trial, the patients answered a questionnaire concerning subjective feelings and side-effects of the treatment.

Simple forewarned visual and auditory RT and MT were studied separately, using a Lafayette apparatus (Model No. 63107 ) according to the technique of Hamsher and Benton. ${ }^{11}$ This technique allows each patient five practice trials followed by 18 trials of warned, simple, visual and auditory RT and MT. After the warning signal (a white light), there is a latency period varying from two to four sec. This latency period was chosen randomly, and all patients were tested in the same random order. Before the warning signal was given, the patients had to press the first of two keys with their index finger (a minimum force of $5 \mathrm{~g}$ was required). At the end of the latency period, a second stimulus appeared (a red light $1 \mathrm{~cm}$ in diameter was placed centrally $1 \mathrm{~m}$ from the patients for the visual test, or a white sound of 80 decibels for the auditory test). The second stimulus was a signal for the patients to release their index finger immediately (RT), and to move it as quickly as possible to the second key (MT). The distance between the keys was $15 \mathrm{~cm}$. The electronic chronometer registered RT and total time $(\mathrm{RT}+\mathrm{MT})$ in msec. The means and standard errors of RT and MT were calculated for 18 trials per patient. The following parameters were determined for each hand: visual RT, visual MT, auditory RT and auditory MT.

CSF was collected by lumbar puncture the day following the RT and MT assessments. As in previous studies, 12 the procedure was carried out on fasting patients between 8:30 and 9:30 a.m. HVA levels were measured by high performance liquid chromatography with fluorometric and electrochemical detection. ${ }^{13}$ CSF HVA values were compared with those of age-matched controls, who underwent myelograms for lumbar disc herniations.

The protocol was approved by the Research Ethics Board of Hôtel Dieu Hospital, and all patients gave their informed consent.

\section{Statistics}

The means of RT and MT measures were compared before and after treatment by the paired t-test. Performance in each test was measured separately for OPCA and FA patients. Since numerous tests were conducted, the initial alpha level, set at 0.05 , was adjusted according to the Bonferoni technique. The adjusted alpha level was $0.05 / 8$ or 0.0063 . All data were analyzed after logarithmic transformation to correct for deviations from normality.

In a second series of tests, pre- and post-treatment measures in FA and OPCA patients were compared taking CSF HVA levels into account. CSF HVA values below $35 \mathrm{ng} / \mathrm{ml}$ were considered low, while those above $35 \mathrm{ng} / \mathrm{ml}$ were deemed to be normal. ${ }^{12}$ Three-way analysis of variance with repeated measures was performed, the main factors being the type of cerebellar damage (OPCA or FA), CSF HVA, and a repeated factor representing measures before and after treatment. All data underwent logarithmic transformation and the alpha level was set at 0.0063 according to the Bonferoni technique. Whenever interactions involving the repeated factor appeared to be significant, simple main effects were calculated to isolate the change within each sub-group included in the interaction.

\section{RESULTS}

In agreement with earlier findings 2.14 .15 the CSF HVA values in FA patients in comparison with their age-matched controls (X $\pm \mathrm{SD})$ were $37.6 \pm 17.5$ versus $51.7 \pm 14.4 \mathrm{ng} / \mathrm{ml}(\mathrm{p}=0.02)$ whereas in OPCA patients they were $36.1 \pm 19.2$ versus $54.1 \pm$ $19.3 \mathrm{ng} / \mathrm{ml}(\mathrm{p}<0.05)$ respectively. Eight of the $17 \mathrm{FA}$ patients and six of the 12 OPCA patients had low HVA values ( $<35 \mathrm{ng} / \mathrm{ml}$ ). AH improved performance by OPCA patients on all but one measure (Table 1). For FA patients, an improvement was noted on only two measures, visual MT and auditory MT 
with the right hand (Table 1). In the three FA and three OPCA patients who had been treated for more than two years, the pattern of response was the same, as assessed clinically. A definite improvement occurred in the first four months, and the patients' condition remained stable after that. Among all the patients treated, only one, who had FA, showed any deterioration.

The second series of statistics takes the CSF HVA levels into account. In OPCA patients, AH improved seven out of eight RT and MT measures (Table 2). Although reductions in RT and MT occurred in OPCA patients with low HVA levels, performance was also improved in OPCA patients with normal HVA values. Improvement occurred in FA patients, but only in four out of eight measures. As with OPCA, it was not confined to patients with low CSF HVA values (Table 2).

The following side-effects were reported in OPCA versus FA patients: sleep disorders and nightmares, $2(17 \%)$ versus 4 $(23.5 \%)$; constipation and nausea, $1(8 \%)$ versus $2(12 \%)$; weight loss, $4(33 \%)$ versus $1(6 \%)$. Finally, a bizarre sensation of heavy legs and stiffness of the legs were noted in only 5 (29\%) FA patients. No cardiac arrythmias were recorded. Only one patient stopped treatment. This was a FA patient who discontinued AH after 1.5 months. All other patients completed at least 3.5 months of treatment with no major side-effects.

In general, self-evaluation of treatment on the part of the patients and their relatives corroborated the objective data from the RT and MT tests. Subjective improvement was striking in OPCA patients, but less evident or absent in FA patients. After the trial, 11 of the 12 OPCA patients and 13 of the 17 FA pati- ents asked to continue the treatment. The others abandoned $\mathrm{AH}$ therapy because of mild side-effects and minimal improvement.

\section{Discussion}

The rationale for using RT and MT tests as objective pre- and post-treatment assessments in this study was two-fold: 1) previous work from our laboratory has demonstrated lengthened RT and MT in patients with cerebellar disease; $16-19$ and 2) no practice effects occur in RT and MT tests. ${ }^{20-23}$ RT is considered to be a test of cognition, measuring the speed and efficiency of information processing. ${ }^{21}$ In more general terms, it evaluates some basic cognitive operations which are involved in many forms of intellectual behavior. $21-25$ RT provides a better prediction of IQ than do other speed of processing tests. ${ }^{25}$ MT strictly evaluates effective motor function, i.e. motor abilities."

Four RT and three MT measures were improved in OPCA patients whereas in FA patients two out of four MT measures were improved, in the absence of improvement on RT measurements. Therefore, in OPCA patients, both the speed of information processing (a cognitive measure) and cerebellar motor abilities in the upper limbs were improved whereas in FA patients only some motor abilities (MT measures with the right hand) were improved.

Certainly we are not able to predict the long-term duration of the improvement observed. By using the functional ataxia scoring scale (FASS), Petersen et al. ${ }^{4}$ calculated the total disability score before and after AH treatment in 16 FA patients in an open clinical trial. The mean percent improvement of the total

Table 1: Effects of AH Treatment

OPCA patients $(n=12)$

FA patients $(n=17)$

\begin{tabular}{|c|c|c|c|c|c|c|c|c|}
\hline Variable & $\begin{array}{l}\text { Pre-treatment } \\
X(m s e c) \pm S D\end{array}$ & $\begin{array}{l}\text { Post-treatment } \\
X(\text { msec }) \pm S D\end{array}$ & t & $\mathbf{p}$ & $\begin{array}{l}\text { Pre-treatment } \\
X(\text { msec }) \pm S D\end{array}$ & $\begin{array}{l}\text { Post-treatment } \\
X(\text { msec }) \pm S D\end{array}$ & $t$ & $\mathbf{p}$ \\
\hline VRT-R & $469.8 \pm 126.3$ & $423 \pm 167.5$ & 5.72 & $<0.001$ & $432.9 \pm 173.9$ & $406.3 \pm 121.9$ & .96 & NS \\
\hline VRT-L & $516 \pm 330.5$ & $407.1 \pm 149.5$ & 3.39 & 0.006 & $454.8 \pm 206.8$ & $447.9 \pm 185.7$ & .32 & NS \\
\hline ART-L & $420.7 \pm 281.9$ & $308.3 \pm 156.8$ & 6.49 & $<0.001$ & $374.2 \pm 147.9$ & $308.3 \pm 156.8$ & 1.67 & NS \\
\hline VMT-R & $608.0 \pm 241.2$ & $477.3 \pm 274.1$ & 6.91 & $<0.001$ & $860.9 \pm 633.9$ & $701.1 \pm 494.3$ & 2.59 & 0.02 \\
\hline VMT-L & $773.3 \pm 492.2$ & $543.2 \pm 294.6$ & 3.23 & 0.008 & $910.4 \pm 595.6$ & $789.9 \pm 580.8$ & 1.51 & NS \\
\hline
\end{tabular}

VRT-R, VRT-L = visual reaction time with the right and left hand respectively.

ART-R, ART-L = auditory reaction time with the right and left hand.

VMT-R, VMT-L, AMT-R and AMT-L = visual movement time with the right and left hand and auditory movement time with the right and left hand NS = not significant respectively.

Table 2: Effects of Amantadine on Reaction Time and Movement Time in OPCA and FA Patients; Relationships with CSF HVA Values

\begin{tabular}{lcrr}
\hline Groups of patients & Variables* & $\begin{array}{c}\text { Pre-treatment } \\
\text { means in msec. }\end{array}$ & $\begin{array}{c}\text { Post-treatment } \\
\text { means in msec. }\end{array}$ \\
\hline OPCA and FA patients & VMT-R & 775.1 & 619.6 \\
with both low and & VMT-L & 869.5 & 698.2 \\
normal CSF HVA levels & AMT-R & 703.7 & 0.001 \\
& AMT-L & 727.1 & 0.003 \\
OPCA patients with & VRT-L & 615.3 & 0.001 \\
low CSF HVA values & & & 0.036 \\
OPCA patients with low & ART-R & 369.5 & 0.0 \\
and normal CSF HVA levels & ART-L & 436.9 & 35.5 \\
\hline
\end{tabular}

*The abbreviations are the same as in Table I 
disability score was $29.5 \%$ whereas for ambulatory patients alone it was $45 \%$. It is difficult to compare our results confined to the upper limbs with those obtained by using the FASS. We believe, however, that the beneficial results are less pronounced than those reported by Petersen et al., ${ }^{4}$ who administered 300 $\mathrm{mg} /$ day of $\mathrm{AH}$, a dosage we never used.

As in all open level studies, we could expect a placebo effect. However, all improvements noted in this trial cannot be ascribed to a placebo effect for the following reasons. RT and MT are sensitive measures and normally do not improve without some specific reason. The method of assessment does not induce practice effects. ${ }^{20-23}$ In a double-blind comparison of folate and thiamine versus placebo, 17 epileptic patients who received four months of placebo treatment showed no reduction of RT and MT over time. 26 Many of them declared that they were improved (i.e. less fatigued, better memory) because they were taking "vitamins" but RT and MT were virtually unchanged.

Parkinsonian features could be encountered in different forms of OPCA syndromes ${ }^{27-29}$ except form 5 (with slow eye saccades).$^{30}$ None of our patients had an extrapyramidal syndrome. In OPCA patients with parkinsonian signs, $\mathrm{AH}$ has been used mostly in combination with levodopa with mild to moderate beneficial results. ${ }^{29}$ There have been no extensive studies reported in the literature on the administration of $\mathrm{AH}$ alone in OPCA patients with or without parkinsonian signs. The beneficial results in our OPCA patients cannot therefore be attributed to an eventual improvement of parkinsonian signs. The antiviral effect of AH is unlikely to be involved in the response of cerebellar ataxia patients. However, $\mathrm{AH}$ also increases rat brain acetylcholine and GABA levels. ${ }^{31}$ The GABA transaminase inhibitor, gamma-vinyl GABA, has no effect in OPCA and FA patients, ${ }^{32}$ and lecithin, a precursor of acetylcholine, is not beneficial in FA. ${ }^{33}$ Dopaminergic mechanisms probably play a role. HVA levels are low in both FA an OPCA patients, and AH is known to release dopamine from neurons. ${ }^{3}$ The mechanism of the decline in dopamine metabolism is unknown, but may result indirectly from neuronal degeneration at distal sites. Two ascending neurochemical pathways originating from the cerebellum have been clearly demonstrated. ${ }^{34}$ The fastigial nucleus sends ipsilateral fibres to the locus ceruleus, the source of the ascending noradrenaline pathway. The interpositus and dentate nuclei send contralateral fibres at the level of the brachium conjonctivum to dopamine-rich areas, including the nucleus ruber, dorsal ventral tegmentum, substantia nigra and nucleus interpedoncularis. Projections from the substantia nigra enter the neostriatum and pass from there to the frontal cortex.

Interactions between the cerebellum and dopaminergic neurons may help to explain why OPCA patients respond better than FA patients to AH. In OPCA, the lesions include cell bodies in the cerebellum, and therefore interactions between damaged neurons and dopaminergic pathways may be direct. In FA, the lesions are mainly spino-cerebellar, and thus interactions between the affected site and dopaminergic neurons are more indirect.

Degeneration of the substantia nigra has been reported in 30$60 \%$ of autopsied cases of different forms of OPCA $; 27-29$ however, this degeneration occurs in later stages of the disease ${ }^{28}$ and could not be accompanied by parkinsonian features. $30 \mathrm{We}$ believe that in both OPCA and FA patients, motor improvement, as measured by MT, is definitely at the cerebellar level for three reasons: i) there is clinically an improvement of motor coordination; none of our patients had parkinsonian rigidity; ii) in FA, there is no anatomical degeneration of the substantia nigra; iii) the deficit of CSF HVA levels is present in both FA and OPCA patients and it is even more pronounced in FA. Concerning the RT improvement limited to OPCA patients, we believe that it is due to the improvement of $\mathrm{AH}$ by cerebello-nigra-striatal-cortical dopaminergic pathways function, without however ruling out microscopic lesions of the substantia nigra not seen on the CT scans of our patients having no clinical parkinsonian signs. Studies on experimental animals strongly support the close relationship between dopaminergic mechanisms and RT performance; $35-37$ on the other hand, experimental, well-delimited cerebellar lesions in monkeys result in a lengthening of RT. ${ }^{38,39}$

Although the effect of $\mathrm{AH}$ on dopamine release ${ }^{3}$ may explain some of its therapeutic actions, it is not the only factor involved. Glutamate is another possible neurotransmitter that must be considered. Our hypothesis is based on three groups of facts. First, anatomical correlates of glutamate toxicity in OPCA have been emphasized and documented by Huang and Plaitakis. ${ }^{10}$ Decreased glutamate catabolism at the nerve terminals results in an increased accumulation of the amino acid released during excitation at the synaptic cleft; this could directly cause a degeneration of postsynaptic neurons. Thus, Purkinje cells that receive glutamatergic innervation by granule cells (parallel fibres) could degenerate in OPCA patients through this mechanism. The deterioration of granule cells and olivopontocerebellar fibres could be due to transneuronal degeneration secondary to the degeneration of Purkinje cells. 10

Second, the neuronal damage associated with neurodegenerative disorders may be related to excitation of $\mathrm{N}$-methyl-D-aspartate receptors. ${ }^{40}$ In particular, Henneberry et al.$^{41}$ demonstrated that the neurotoxicity of glutamate and closely-related agonists is mediated by NMDA receptors in rat cerebellar granule cells.

Third, memantine, an analog of $\mathrm{AH}$, is a potent blocker of NMDA receptor channels. 42,43 We believe that AH's action on NMDA receptor channels provides a second explanation of the clinical improvement observed in our cases. This action is exerted strictly at the cerebellar level and may also explain why the improvement is more pronounced in OPCA than in FA patients.

Further double-blind clinical studies and simultaneous experimental investigations are needed to explore a more comprehensive replacement therapy in heredo-degenerative ataxias.

\section{ACKNOWLEDGEMENTS}

The authors thank Dr. Robert Lalonde for improving the manuscript with his helpful suggestions. Mr. Yves Courchesne, B.Sc.Pharm., and Mr. François Lemire, B.Sc.Pharm., provided invaluable pharmacological support. Amantadine hydrochloride pills were generously donated by Dupont Canada Inc. Mr. Marc Dumont, M.Sc., was responsible for the statistical analyses. Technical assistance was rendered by Mrs. Michèle Mathieu and Mrs. Ana De Oliveira.

Supported by grants from Fonds de la Recherche en Santé du Québec, the Canadian Association of Friedreich's Ataxia (to M.I.B.) and the Medical Research Council of Canada (to S.N.Y.). 


\section{REFERENCES}

I. Botez T, Botez MI, Parent C, et al. Etude préliminaire évaluant l'effet a court terme de l'amantadine et du L-tryptophane associé au carbidopa dans le traitement des ataxies spinocérébelleuses. Medecine/sciences 1988; 46A: (Suppl. 1).

2. Botez MI, Young SN, Botez T, et al. Treatment of Friedreich's ataxia with amantadine. Neurology 1989; 39: 749-750 (letter).

3. Von Voigtlander P, Moore K. Dopamine: release from the brain in vivo by amantadine. Science 1970; 174: 408-410.

4. Petersen PL, Saad J, Nigro MA. The treatment of Friedreich's ataxia with amantadine hydrochloride. Neurology 1988; 38: 14781480.

5. Noica D, Draganesco S. Sur un symptôme caractéristique d'une lésion des noyaux centraux moteurs: la rigidité musculaire latente. Rev Neurol 1935; 63: 75-79.

6. Botez MI. Frontal lobe tumours. In: Vinken PJ and Bruyn GW, eds. Handbook of Clinical Neurology, Vol. 17, Part II, Amsterdam; North Holland 1974: 234-280.

7. Botez, MI, Attig E, Vezina JL. Cerebellar atrophy in epileptic patients. Can J Neurol Sci 1988; 15: 299-303.

8. Smedley hand dynamometer. Manual. Catalog number 19117 , Stoelting Company, Chicago (IL), 1972, 2 pp.

9. Harding AE. The inherited ataxias. $I n$ : Di Donato $S$, et al., eds. Advances in Neurology, Vol. 48: Molecular Genetics of Neurological and Neuromuscular Disease. New York; Raven Press 1988: 37-45.

10. Huang YP, Plaitakis A. Morphological changes of olivopontocerebellar atrophy in computed tomography and comments on its pathogenesis. In: Duvoisin RC and Plaitakis A, eds. The Olivopontocerebellar Atrophies. Advances in Neurology, New York, Raven Press 1984; 41: 39-86.

11. Hamsher KS, Benton AL. The reliability of reaction time determinations. Cortex 1977; 3: 306-310.

12. Botez MI, Young SN. Effects of anticonvulsant treatment and low levels of folate and thiamine on amine metabolites in cerebrospinal fluid. Brain 1991; 114: 333-348.

13. Anderson GM, Young SN, Cohen DJ. Rapid liquid chromatography determination of tryptophan, tyrosine, 5-hydroxyindoleacetic acid and homovanillic acid in cerebrospinal fluid. J Chromatogr 1979; 164: 501-505.

14. Ichikawa N. Study on monoamine metabolite contents of cerebrospinal fluid in patients with neurodegenerative diseases. Tohoku J Exp Med 1986; 150: 435-446.

15. Polinsky RJ, Brown RT, Burns RS, et al. Low lumbar CSF levels of homovanillic acid and 5-hydroxyindoleacetic acid in multiple system atrophy with autonomic failure. J. Neurol Neurosurg Psychiatry 1988; 51: 914-919.

16. Botez MI, Gravel J, Attig E, et al. Reversible chronic cerebellar ataxia after phenytoin intoxication: possible role of cerebellum in cognitive thought. Neurology 1985; 35: 1152-1157.

17. Botez MI, Botez T, Elie R, et al. Role of the cerebellum in complex human behavior. Ital J Neurol Sci 1989; 10: 291-300.

18. Botez T, Botez MI, Cardu B, et al. Speed of information processing and its relationship to intelligence at various levels of the central nervous system. Neurology 1989; 39: 318 (Suppl. 1) (abstract)

19. Botez MI, Leveille J, Botez T. Role of the cerebellum in cognitive thought. In: Matheson $\mathrm{M}$ and Newman $\mathrm{H}$, eds. Proceedings of the Thirteenth Annual Brain Impairment Conference, Australian Society for the Study of Brain Impairment, Sydney 1989: 179-195.

20. Benton AL, Blackburn HL. Practice effects in reaction time tasks in brain-injured patients. J Abn Soc Psychol 1957; 54: 109-113.

21. Vernon PA. Speed of information processing and general intelligence. Intelligence 1983; 7: 53-70.

22. Ladurner $G$, Tschinkel $M$, Klebb $H$, et al. Reaction time in cerebrovascular disease. Arch Gerontol Geriat 1985: 4: 373-379.
23. Baker SJ, Maurissen JP, Chrzan GJ. Simple reaction time and movement time in human volunteers. Percept Motor Skills 1986; 63: 767-774

24. Jensen AR, Munro E. Reaction time, movement time and intelligence. Intelligence 1979; 3: 121-126.

25. Vemon PA. Reaction time and intelligence in the mentally retarded. Intelligence 1981; 5: 345-355.

26. Botez MI, Gravel J, Ross-Chouinard A, et al. Folate and thiamine treatment in epileptic patients. Neurology 1987; 37: 349 (Suppl. 1) (abstract).

27. Schut JW, Haymaker W. Hereditary ataxia: Pathological study of 5 cases of common ancestry. J Neuropathol Clin Neurol 1951; 1: 183-213.

28. Caplan LR. Clinical features of sporadic (Dejerine-Thomas) olivopontocerebellar atrophy. In: Duvoisin RC and Plaitakis A, eds. The Olivopontocerebellar Atrophies. Advances in Neurology, Vol. 41, New York; Raven Press 1984: 217-224.

29. Goetz CG, Tanner CM, Klawans HL. The pharmacology of olivapontocerebellar atrophy. In: Duvoisin RC and Plaitakis A, eds. The Olivopontocerebellar Atrophies. Advances in Neurology, New York; Raven Press 1984; 41: 143-148.

30. Wadia $\mathrm{NH}$. A variety of olivopontocerebellar atrophy distinguished by slow eye movements and peripheral neuropathy. $m$ : Duvoisin $\mathrm{RC}$ and Plaitakis A, eds. The Olivopontocerebellar Atrophies. Advances in Neurology, New York; Raven Press 1984; 41 : 149177.

31. Bak L, Hassler R, Kim J, et al. Amantadine actions on acetylcholine and GABA in striatum and substantia nigra of rat in relation to behavioral changes. J Neurol Transm 1972; 33: 4561.

32. Bonnet AM, Esteguy M, Tell G, et al. A controlled study of oral Vigabatrin (gamma-vinyl GABA) in patients with cerebellar ataxia. Can J Neurol Sci 1986; 13: 331-333.

33. Pentland B, Martyn CN, Steer RC, et al. Lecithin treatment in Friedreich's ataxia. Br Med J 1981; 282: 1197.

34. Snider RA, Maiti A, Snider SR. Cerebellar pathways to ventral midbrain and nigra. Exp Neurol 1976; 53: 714-728.

35. Amalric M, Koob GF. Depletion of dopamine in the caudate nucleus but not in nucleus accumbens impairs reaction-time performance in rats. J Neurosci 1987; 7: 2129-2134.

36. Sawaguchi T. Catecholamine sensitivities of neurons related to a visual reaction time task in the monkey prefrontal cortex. J Neurophysiol 1987; 58: 1100-1122.

37. Rinne JO, Rummukainen J, Paljarvi L, et al. Dementia in Parkinson's disease is related to neuronal loss in the medial substantia nigra. Ann Neurol 1989; 26: 47-50.

38. Lamarre Y, Jacks B. Involvement of the cerebellum in the initiation of fast ballistic arm movement in the monkey. Contemp Clin Neurophysiol 1978; 34 (2): $441-447$ (EEG, Suppl.).

39. Spidalieri G, Busby L, Lamarre Y. Fast ballistic arm movements triggered by visual, auditory and somesthetic stimuli in the monkey. II. Effects of unilateral dentate lesion on discharge of precentral cortical neurons and reaction time. J Neurophysiol 1983: 50: $1359-1379$.

40. Cox JA, Lysko PG, Henneberry RC. Excitatory amino acid neurotoxicity at the N-methyl-D-aspartate receptor in cultured neurons: role of the voltage dependent magnesium block. Brain Res 1989; 499: 266-272.

41. Henneberry RC, Novelli A, Cox JA, et al. Neurotoxicity at the Nmethyl-D-aspartate receptor in energy-compromised neurons. Ann NY Acad Sci 1989; 558: 225-233.

42. Bormann J. Memantine is a potent blocker of N-methyl-D-aspartate (NMDA) receptor channels. Eur J Pharmacology 1989; 166: 591-592.

43. Kornhuber J, Bormann J, Retz W, et al. Memantine displaces $(3 \mathrm{H})$ MK-80I at therapeutic concentrations in postmortem human frontal cortex. Eur J Pharmacol 1989; 166: 589-590. 